\title{
Application of Selected Methods of Artificial Intelligence to Activated Sludge Settleability Predictions
}

\author{
Bartosz Szeląg*, Jarosław Gawdzik** \\ Faculty of Environmental, Geomatic and Energy Engineering, Kielce University of Technology, \\ Al. Tysiąclecia Państwa Polskiego 7, 25-314 Kielce, Poland
}

Received: 9 December 2015

Accepted: 18 March 2016

\begin{abstract}
In the study, the results of measurements of inflow (Q), wastewater temperature in the chamber $(\mathrm{T})$, a degree of external $\left(\mathrm{REC}_{\mathrm{ext}}\right)$ and internal $\left(\mathrm{REC}_{\text {int }}\right)$ recirculation in the biological-mechanical wastewater treatment plant in Cedzyna near Kielce, Poland were used to make predictions of settleability of activated sludge. Three methods, namely genetic programming, the Support Vector Machines method and artificial neural networks were employed to compute activated sludge settleability. The results of analyses indicate that artificial neural networks demonstrate the best predictive abilities. That is confirmed by the values of parameters that describe simulation fit to sludge settleability measurement data for inputs of concern.
\end{abstract}

Keywords: genetic programming, support vector machines, artificial neural networks, sludge settleability

\section{Introduction}

Currently, activated sludge treatment is a basic method of biological treatment of wastewater that originates from both large agglomerations and small settlements. The amount of influent urban wastewater is primarily affected by daily water consumption per person and the number of residents in the catchment area. In industrialised countries, the unit water consumption per person per day ranges $120 \div 175 \mathrm{dm}^{3} / \mathrm{p} / \mathrm{d}$ [1]. In the classic activated sludge process, mechanically treated wastewater is delivered to the aeration tank, where it is mixed with activated sludge. The latter looks like a flocculant suspension. It is assumed that $1 \mathrm{~g}$ of dry mass (DM) of activated sludge has an area

*e-mail: bartoszszelag@op.pl

**e-mail: jgawdzik@tu.kielce.pl of 100-200 $\mathrm{m}^{2}$ [2]. Activated sludge floc is composed of numerous different microorganisms, mainly heterotrophic bacteria, and also organic and inorganic particles. Extracellular polymeric substances are also found, which together with other building material, are responsible for floc properties and structure, flocculation ability, settleability and hydration. Microorganisms constitute up to $20 \%$ of the floc volume, whereas the remaining part are colloidal substances. Components of the colloidal part include polysaccharides, lipids, proteins, fatty acids, humic substances and numerous heteropolymers. The nuclei of activated sludge floc consist mainly of clays $(\mathrm{Si}, \mathrm{Fe}, \mathrm{Al})$, calcium orthophosphates and iron oxides [3]. Small-pore floc has poor settleability, whereas large and thick floc shows substantial settleability of particles. Poorly settling floc is very difficult to dehydrate, therefore obtaining floc that has optimal properties is essential for the appropriate course of activated sludge treatment 
$[2,3]$. Tests of settleability, performed systematically, make it possible to obtain information on problems that occur in activated sludge operation, and to take a corrective action. Settleability of activated sludge is a relevant parameter which decides on the value of the sludge index, which is correlated to suspended solids content in the treated wastewater [4]. In view of the above, it is necessary to monitor suspended solids content on continuous basis. However, no attempts have been made to model this parameter with numerical methods based on physical or stochastic models, or with black box methods.

Software, including GPS-X, WEST, STOAT, BioWin, SIMBA, and others, is widely used to assess the treatment facility operation, and variation in technological parameters of both activated sludge and wastewater. To be able to calibrate the mathematical model in the applications mentioned above, it is necessary to collect key information on processes that occur in individual parts of the treatment facility. Due to a large number of parameters that need to be accounted for, and especially because of the effect of uncertainty of the estimated parameters in the models, the calibration of the model is not an easy task [5]. Consequently, to model the processes going on in the individual parts of the treatment plant, i.e. degree of pollutant load reduction (suspended solids, biogenic compounds), to optimise the operation of the treatment plant parts (determination of oxygen amount in activated sludge tanks, the electrical energy used in pumping stations), and also to produce biogas, artificial neural networks [6-9], genetic programming [10], Support Vector Machines (SVM) [11-13], autoregressive models [14], regression trees [15-16], and others are used.

It is therefore purposeful to develop mathematical models for predicting settleability over an arbitrary time interval. This paper presents the application and results of settleability computations obtained with artificial neural networks, Support Vector Machines and genetic programming, in which an arbitrary time step between individual measurements of a given parameter was allowed. For the sake of analysis, results of continuous measurements taken from 16 June 2011 to 09 August 2013 were used. The measurements included the following: the technological parameter of concern of the activated sludge, temperature and amount of the inflowing wastewater, the degree of its external recirculation (from the secondary settling tank to the bioreactor) and of internal recirculation (from the aerobic chamber to the anaerobic chamber in the bioreactor), and the amount of surplus sludge removed from the bioreactor.

\section{The Object of Investigations}

The facility in Cedzyna near Kielce, Poland, is a mechanical-biological wastewater treatment plant, having a capacity of $\mathrm{Q}_{\mathrm{dś} r}=1215 \mathrm{~m}^{3} / \mathrm{d}$, with aerobic sludge stabilisation. The size of the facility reflected by the population equivalent is $\mathrm{PE}=9466$. Raw wastewater inflowing via the sanitary sewer is directed to the grit chamber and the grease trap, and then to the pumping station. From the pumping station, wastewater is introduced, through the separation chamber, to the bioreactor, where wastewater is returned from the aerobic to the anaerobic part, and surplus sludge is delivered to the separate tank (sludge pumping is switched on every two hours). Dehydrated wastewater sludge is periodically transported to the landfill in Promnik near Kielce. From the bioreactor, wastewater flows to the secondary settling tank, from where it is pumped for recirculation. Treated wastewater is discharged into the Lubrzanka river.

\section{Materials and Methods}

In the investigations into predictions of activated sludge settleability (SE) in the bioreactor chamber, the results of the following measurements were used: inflow (Q), wastewater temperature in the chamber (T), degree of external $\left(\mathrm{REC}_{\mathrm{ext}}\right)$ and internal $\left(\mathrm{REC}_{\text {int }}\right)$ recirculation. The measurements were taken from 16 June 2011 to 09 August 2013. For the calculations of activated sludge settleability, three methods were used, namely genetic programming, Support Vector Machines and artificial neural networks. As settleability was measured a few times (twice to four times) a day at different time intervals (in the morning, at noon, in the afternoon and in the evening or in the step $1 \div 6$ hour), in the analyses conducted for the study, an option was offered to model the parameter of concern with a time step forward.

In this paper, many combinations of input data that provided the basis for settleability computations were analysed. Additionally, in all variants of concern, degree of external $\left(\mathrm{REC}_{\mathrm{ext}}\right)$ and internal $\left(\mathrm{REC}_{\mathrm{int}}\right)$ recirculation. First, the possibility of predicting the value of settleability $\mathrm{SE}(\mathrm{t})$ on the basis of temperature $\mathrm{T}(\mathrm{t})$ and instantaneous wastewater inflow $\mathrm{Q}(\mathrm{t})$ was considered. That was aimed at finding out whether it was necessary to take measurements of the technological parameter of concern. The next option to be analysed was predicting settleability exclusively on the basis of flow values, namely $\mathrm{Q}(\mathrm{t}-1)$, $\mathrm{Q}(\mathrm{t}-2)$, and also wastewater temperature, i.e. $\mathrm{T}(\mathrm{t}-1)$, $\mathrm{T}(\mathrm{t}-$ 2). Finally, the possibility of modelling settleability on the basis of previous measurements of SE was investigated. The goal of the analyses was to determine the effect of input quantitative data (wastewater inflow), technological parameters of the bioreactor (temperature, preceding values of settleability) and to examine the possibility of using those data to predict the discrete values of OP. Due to the fact that in the analyses, the results concerning the quality of wastewater flowing into the treatment plant and recirculated aquaculture concentration were not available, it was not possible to build a physical model, which is indicated in numerous studies [17-19].

An interesting method of finding discriminant functions has been proposed by Vapnik, who termed the method Support Vector Machines (SVM) [20]. As the method has proved to be effective and fast, Vapnik has also applied it to regression issues. As in regression problems, 
the relation between interpreted variable y and interpretive variables can be linear in character, in the SVM method, linear transformation $\varphi: \mathrm{X}^{\mathrm{L}} \rightarrow \mathrm{Z}$ is used, i.e. observations in the training set are transformed into space of much larger dimensions. In this method, in the goal function definition, the so-called error function with insensitive threshold $\varepsilon$ is used, which is expressed as follows [21]:

$$
L^{\varepsilon}(d, y(x))=\left\{\begin{array}{lll}
0 & \text { for } & |d-f(x)| \leq \varepsilon \\
|d-y(x)|-\varepsilon & \text { for } & |d-f(x)|>\varepsilon
\end{array}\right.
$$

where: $\varepsilon$ - assumed model accuracy, $\mathrm{x}$ - input vector, $y(x)$ - value of the model output signal, expressed by the dependence:

$$
y(x)=\sum_{j=1}^{K} w_{i} \cdot \varphi_{i}(x)+b=w^{T} \cdot \varphi(x)+b
$$

...where $\mathrm{w}=\left[\mathrm{w}_{1}, \ldots, \mathrm{w}_{\mathrm{k}}\right]^{\mathrm{T}}-$ transposed vector of weights, $\varphi(\mathrm{x})=\left[\varphi_{1}(\mathrm{x}), \ldots, \varphi_{\mathrm{k}}(\mathrm{x})\right]-$ vector of basis functions.

In the SVM method, the training of the network involves the minimisation of the error function, having the form:

$$
R=\frac{1}{p} \sum_{i=1}^{p} L_{\varepsilon}\left(d_{i}, y\left(x_{i}\right)\right.
$$

in which: $\mathrm{p}$ - number of trained pairs $\left(\mathrm{x}_{\mathrm{i}}, \mathrm{d}_{\mathrm{i}}\right)$.

After complementary variables $\xi_{\mathrm{i}}$ and $\xi_{\mathrm{i}}$, are taken into account, the problem of network training can be reduced to the following dependence [21]:

$$
\phi\left(w, \xi, \xi^{\prime}\right)=C\left[\sum_{i=1}^{p}\left(\xi_{i}+\xi_{i}^{\prime}\right)\right]+\frac{1}{2} \cdot w^{T} w
$$

on condition that the following constraints are satisfied:

$$
\left\{\begin{array}{l}
d_{i}-w^{T} \varphi(x) \leq \varepsilon+\xi_{i} \\
w^{T} \varphi(x)-d_{i} \leq \varepsilon+\xi_{i} \\
\xi_{i} \geq 0 \\
\xi_{i}^{\prime} \geq 0
\end{array}\right.
$$

Constant $\mathrm{C}$ in formula (4) is selected by the user depending on $\varepsilon$ [21]. Using the method of Lagrangian multipliers $\left(\alpha_{\mathrm{i}}\right)$, the set of equations defined by equations (4) and (5) can be reduced to a dual problem. The solution to the problem, presented in the form dependent on the so-called kernel function $\mathrm{K}$, can be written as follows [21]:

$$
y(x)=\sum_{i=1}^{N_{s}}\left(\alpha_{i}-\alpha_{i}^{\prime}\right) K\left(x, x_{i}\right)+w
$$

in which: $\mathrm{N}_{\mathrm{sv}}$ - number of support vectors, dependent on $\mathrm{C}$ and $\varepsilon$. The most frequently used kernel functions are linear, polynomial and Gaussian kernels. In this study, for computations Gaussian kernels were applied, and it was assumed that $\varepsilon=0.01$ while $C$ is set at the stage of analysis.

\section{Genetic Programming}

Koza [22] proposed a special type of evolution algorithm, termed genetic programming (GP). It is an extension of a genetic algorithm (GA) applied to design programs having a form of the so-called parse trees that solve a problem posed. The model is based on the process of collective training of the population of points, called individuals. In GP, an individual is represented by a tree that has nodes randomly selected from two sets: tree leaves are determined from the set of terminal arguments $(\mathrm{T})$ and the remaining nodes - from the set of functions (F). Depending on the type of function $\mathrm{T}$ or $\mathrm{F}$, an individual may be a logical expression, or a mathematical function. The terminal set can be composed of independent variables that describe a given phenomenon (temperature, wastewater inflow, settleability measured in a time step $\Delta \mathrm{t}$ from the prediction value) and constants. The set of functions contains basic mathematical operators $(+,-, /$, sine, cosine, exp., etc.) which can be used at the stage of model construction. The evolution process starts with a random selection of $\mathrm{n}$ individuals of the population. Next, four operations are applied repeatedly (generations): reproduction, genetic operations, evaluation and succession, and those go on until the algorithm stopping criterion is met. Stochastic reproduction operator involves the selection, from the current population, of $\mathrm{n}$ parent individuals who ensure the generation of offspring. Genetic operators are applied to parent individuals, in order to mix the information contained in them by means of crossover and mutation. The offspring individuals created in this way undergo evaluation, i.e. the value of the optimised quality criterion, called the fitness function, is determined.

Point mutation substitutes a function or a terminal in a selected part of the tree for another function or terminal within the same tree. On the other hand, the subtree mutation randomly replaces whole subtrees with other subtrees, thus creating new ones. Subtree crossover is regarded as the most important genetic programming operator, which creates new trees by substituting randomly selected subtrees in the existing trees.

In this study, the correlation coefficient provided the criterion of fit of given computation results, obtained using the mathematical formula based on GP, to the measurement data. To construct a model for settleability predictions, basic mathematical operators of the type ,,$+- /$, - were used, also the probability of mutation was assumed to be $P_{m}=0.25$ and that of crossover $P_{c}=0.65$. 


\section{Artificial Neural Networks}

Neural networks are widely used because they can be applied to simulations of linear and non-linear processes, optimisation, classification and control [2325]. The most common neural networks structure is multilayer perceptron (MLP), in which input signals $\left(\mathrm{x}_{\mathrm{i}}\right)$ are multiplied by values of weights $\left(\mathrm{w}_{\mathrm{ij}}\right)$, and then passed to the hidden layer neurons, where in the individual neurons the summation occurs $\sum \mathrm{z}_{\mathrm{m}}=\mathrm{x}_{\mathrm{n}} \cdot \mathrm{w}_{\mathrm{nm}}-\mathrm{b}_{\mathrm{j}}$, (where: $\mathrm{m}$ - number of neurons in the network, $b_{1, k}-$ threshold, or the so-called bias). The sums obtained $\left(\sum \mathrm{x}_{\mathrm{j}}\right)$ are transformed using the linear or non-linear activation function (f), and are relayed to output neurons. Finding optimal values of weights $\left(\mathrm{w}_{\mathrm{ij}}\right)$ for individual neurons is obtained by means of training. Prior to the start of the construction of mathematical models, input and output signals were standardised using the dependence:

$$
\bar{A}_{i}=\frac{A_{i}-\min A}{\max A-\min A}
$$

...where: $\bar{A}_{\mathrm{i}}$ - standardised value of the $i$-th element of the A set obtained with the min-max method, $A_{i}$ - value of the $i$-th element of the A set recorded in measurements, max $\mathrm{A}$ - maximum value of a single element in the A parameter set, min A - minimum value of a single element in the A parameter set.

Due to the lack of guidelines on the selection of neural network structure for settleability predictions, the STATISTICA software automatic designer function was used in computations. In the simulations conducted for the study, 500 different neural networks were generated for each input data combination. Also, the parameters of computation fit to measurement data were determined. In the analyses, it was assumed that in the models, the number of neurons in the hidden layer ranged $2 \div 10$. Hyperbolic tangent activation function was assumed in the layer of hidden neutrons, whereas in the output layer it was a linear function. In order to make the training process in the models (ANN, GP and SVM) appropriate, and then to properly assess the performance of those models, the data were partitioned into three sets (training $-50 \%$, validating $-25 \%$ and testing $-25 \%$ ). The neural network training was implemented using the Broyden - Fletcher - Goldfarb - Shanno algorithm [25].

\section{Criteria for the Model Assessment}

In the analyses above, to assess the predictive ability of the models for settleability predictions, commonly used measures were applied, which include:

- mean error (MAE)

$$
\text { MAE }=\frac{1}{n} \cdot \sum_{i=1}^{n}\left|y_{i, o b s}-y_{i, p r e d}\right|
$$

$$
\text { MAPE }=\frac{1}{n} \cdot \sum_{i=1}^{n}\left|\frac{y_{i, o b s}-y_{i, p r e d}}{y_{i, o b s}}\right| \cdot 100 \%
$$

where: $\mathrm{y}_{\mathrm{i}, \mathrm{obs}{ }^{\prime} \text { obl }}-$ settleability values, measured and computed, respectively, $\mathrm{n}$ - size of the set, which was $\mathrm{n}=2546$.

\section{Computation Results}

Analyses performed for the study (Tables 1 and 2) indicate that the models based on artificial neural networks show far better predicting abilities as regards settleability than those constructed using the SVM method. That was unambiguously confirmed by the respective values of errors in model fit to measurement data. Additionally, in the obtained neural networks (Table 2), the number of neurons in the hidden layer ranged from 2 to 6 , and the value $\mathrm{C}$ in the model obtained based on the SVM equal $9 \div 12$. On the basis of the calculations performed, it can be stated that for such input signals as $\mathrm{Q}, \mathrm{T}$ and $\mathrm{REC}_{\mathrm{ext}}$ int , the best predictions are obtained with ANN, which is confirmed by the values of parameters MPE $=19.28 \%$ and $\mathrm{MAE}=$ $72.18 \mathrm{~cm}^{3} / \mathrm{dm}^{3}$ expressing errors in the prediction per a single value of SE. Conversely, the genetic programming method shows the worst predicting abilities for the inputs mentioned above. In GP, settleability is expressed as follows:

$$
\begin{aligned}
& S E(t)=A(t)-5 \cdot T(t)-2 \cdot R E C_{z}(t)+\frac{Q(t)+1}{R E C_{z}(t)}+0,15 \\
& A(t)=\frac{26,6 \cdot\left(4 \cdot R E C_{z}(t)+2 \cdot R E C_{z}(t) \cdot T(t)+0,03\right)}{T(t)}
\end{aligned}
$$

and the values of mean absolute and relative errors are equal to: $\mathrm{MAE}=43.21 \mathrm{~cm}^{3} / \mathrm{dm}^{3}$ and $\mathrm{MAPE}=23.18 \%$, respectively.

Table 1. Comparison of the accuracy of predictions for the mathematical models developed using the SVM method.

\begin{tabular}{|c|c|c|c|c|}
\hline \multirow{2}{*}{ Data } & \multicolumn{2}{|c|}{ Trained set } & \multicolumn{2}{c|}{ Test set } \\
\cline { 2 - 5 } & $\begin{array}{c}\text { MAE, } \\
\mathrm{cm}^{3} / \mathrm{dm}^{3}\end{array}$ & $\begin{array}{c}\text { MAPE, } \\
\%\end{array}$ & $\begin{array}{c}\text { MAE, } \\
\mathrm{cm}^{3} / \mathrm{dm}^{3}\end{array}$ & $\begin{array}{c}\text { MAPE, } \\
\%\end{array}$ \\
\hline $\mathrm{Q}(\mathrm{t}), \mathrm{T}(\mathrm{t})$ & 101.71 & 31.89 & 88.86 & 24.50 \\
\hline $\mathrm{Q}(\mathrm{t}-1)$ & 149.88 & 50.05 & 145.55 & 49.55 \\
\hline $\mathrm{Q}(\mathrm{t}-1), \mathrm{Q}(\mathrm{t}-2)$ & 141.28 & 45.78 & 135.78 & 44.16 \\
\hline $\mathrm{T}(\mathrm{t}-1)$ & 85.86 & 24.16 & 86.34 & 32.97 \\
\hline $\mathrm{T}(\mathrm{t}-1), \mathrm{T}(\mathrm{t}-2)$ & 70.28 & 19.39 & 68.08 & 29.03 \\
\hline $\mathrm{SE}(\mathrm{t}-1)$ & 39.43 & 9.97 & 43.03 & 18.91 \\
\hline $\mathrm{SE}(\mathrm{t}-1), \mathrm{T}(\mathrm{t}-1)$ & 38.98 & 9.57 & 40.59 & 14.19 \\
\hline
\end{tabular}


Table 2. Comparison of the accuracy of predictions for the mathematical models developed using artificial neural networks (ANN).

\begin{tabular}{|c|c|c|c|c|c|}
\hline \multirow{2}{*}{ Data } & & \multicolumn{2}{|c|}{ Trained set } & \multicolumn{2}{c|}{ Test set } \\
\cline { 2 - 6 } & $\begin{array}{c}\text { Neuron } \\
\text { number }\end{array}$ & $\begin{array}{c}\text { MAE, } \\
\mathrm{cm}^{3} / \mathrm{dm}^{3}\end{array}$ & $\begin{array}{c}\text { MAPE, } \\
\%\end{array}$ & $\begin{array}{c}\text { MAE, } \\
\mathrm{cm}^{3} / \mathrm{dm}^{3}\end{array}$ & $\begin{array}{c}\text { MAPE, } \\
\%\end{array}$ \\
\hline $\begin{array}{c}\mathrm{Q}(\mathrm{t}), \\
\mathrm{T}(\mathrm{t})\end{array}$ & 4 & 70.47 & 17.96 & 72.18 & 19.28 \\
\hline $\mathrm{Q}(\mathrm{t}-1)$ & 4 & 94.18 & 32.12 & 98.63 & 36.44 \\
\hline $\begin{array}{c}\mathrm{Q}(\mathrm{t}-1), \\
\mathrm{Q}(\mathrm{t}-2)\end{array}$ & 3 & 71.22 & 25.03 & 63.12 & 24.51 \\
\hline $\mathrm{T}(\mathrm{t}-1)$ & 2 & 50.37 & 24.16 & 57.14 & 19.37 \\
\hline $\begin{array}{c}\mathrm{T}(\mathrm{t}-1), \\
\mathrm{T}(\mathrm{t}-2)\end{array}$ & 2 & 46.23 & 17.25 & 52.01 & 15.12 \\
\hline $\mathrm{SE}(\mathrm{t}-1)$ & 3 & 38.95 & 12.96 & 39.16 & 9.19 \\
\hline $\begin{array}{c}\mathrm{SE}(\mathrm{t}-1), \\
\mathrm{T}(\mathrm{t}-1)\end{array}$ & 6 & 33.66 & 10.78 & 36.63 & 8.75 \\
\hline
\end{tabular}

...where: $\mathrm{Q}(\mathrm{t}-1, \mathrm{t}-2), \mathrm{T}(\mathrm{t}-1, \mathrm{t}-2), \mathrm{SE}(\mathrm{t}-1)$ - flow to the treatment plant, wastewater temperature, and settleability measured in a time step $\Delta \mathrm{t}$ from the predicted value of the technological parameter, $\mathrm{Q}(\mathrm{t}), \mathrm{T}(\mathrm{t})$ - inflow and temperature specified at the same time as $\mathrm{SE}(\mathrm{t})$.

Additionally, computations carried out for the study show that the mathematical models relying on artificial neural networks have far better predictive abilities as regards settleability when values of wastewater flow $\mathrm{Q}(\mathrm{t}-1)$ and $\mathrm{Q}(\mathrm{t}-2)$ to the treatment plant are used, than those based on the SVM method. For instance, for OP(t) predictions based on $\mathrm{Q}(\mathrm{t}-1)$, the model contingent on ANN gave relative and absolute error values of MAPE $=36.44 \%$ and $\mathrm{MAE}=98.63 \mathrm{~cm}^{3} / \mathrm{dm}^{3}$. For the model developed on the basis of the SVM, the parameters of computation fit to measurements were $\mathrm{MAPE}=49.55 \%$ and $\mathrm{MAE}=145.55 \mathrm{~cm}^{3} / \mathrm{dm}^{3}$.

The analysis of simulation results (Tables 1 and 2) demonstrates that much better predictive abilities with respect to $S E(t)$ are found for models developed on the basis of wastewater temperature measured in time step

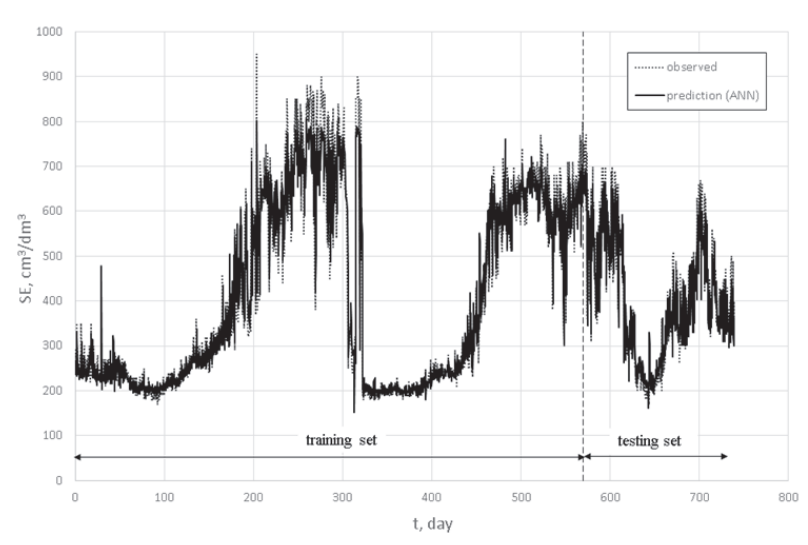

Fig. 1. Comparison of predictions of the best model for ANN predicting and observed activated sludge settleability.
$\Delta \mathrm{t}$ from the predicted value of the technological parameter than for the models obtained on the basis of wastewater flow to the treatment plant. For instance, the values of the relative and absolute error in the model developed with the SVM on the basis of T(t-1) are equal to $\mathrm{MAE}=86.34 \mathrm{~cm}^{3} / \mathrm{dm}^{3}$ and MAPE $=32.97 \%$. Also, on the basis of analyses (Tables 1 and 2), it can be seen that taking into account an additional variable, i.e. wastewater temperature $\mathrm{T}(\mathrm{t}-2)$, in the model leads to improvement in the prediction of the technological parameter in cases under consideration. In the models based on SVM and ANN (Table 1), taking into account an additional variable $\mathrm{T}(\mathrm{t}-2)$ results in reduced values of MAE by $26.5 \%$ and of MAPE by $13.8 \%$, and also MAE by $9.9 \%$ and MAPE by $28.0 \%$, respectively. The analysis of results (Tables 1 and 2) shows that best predictive abilities as regards SE are found in the models in which the results of previous measurements were incorporated $\mathrm{SE}(\mathrm{t}-1)$. When settleability is modelled exclusively on the basis of the previous value of SE, absolute and relative errors are MAE $=39.16 \mathrm{~cm}^{3} / \mathrm{dm}^{3}$ and MAPE $=9.19 \%$ for ANN, and $\mathrm{MAE}=39.16 \mathrm{~cm}^{3} / \mathrm{dm}^{3}$ and MAPE $=9.19 \%$ for SVM. Additionally, when the model for predicting $S E=f(S E(t-1))$ accounts for the wastewater temperature in the previous measurement in the time step $\Delta t$, the error in computation fit to measurement data is reduced. To visualise the results obtained of the best model artificial neural network, Fig. 1 shows the comparison of forecasts predicting and measurements activated sludge settleability.

On the basis of the results (Tables 1 and 2), it can be stated that to determine the settleability of the activated sludge in real time $\mathrm{SE}(\mathrm{t})$ using $\mathrm{ANN}$ or SVM, it is sufficient to use the following: the result of the previous measurement of $\mathrm{SE}(\mathrm{t}-1)$, wastewater temperature $\mathrm{T}(\mathrm{t}-1)$ in the bioreactor, and the degree of external ( $\left.\mathrm{REC}_{\mathrm{z}}\right)$ and internal $\left(\mathrm{REC}_{\mathrm{w}}\right)$ recirculation. That is confirmed by the calculated values of correlation coefficients, and those of both absolute ME and relative MPE errors. In view of the findings above, the following regression model for the prediction of settleability was developed:

$$
S E(t)=S E(t-1)+\frac{\left(\frac{S E(t-1)}{T(t-1)}-S E(t-1) \cdot \Delta t^{2}\right)}{R E C_{e x t} \cdot(S E(t-1))^{4}}
$$

The regression dependence (11) is capable of producing high-accuracy settleability predictions $\mathrm{SE}(\mathrm{t}-1)$, as the values of MAE and MPE are $41.25 \mathrm{~cm}^{3} / \mathrm{dm}^{3}$ and $16.52 \%$, respectively. Although error values are lower than those obtained with the ANN (Table 1), dependence (11) will not be troublesome to use by the staff who operate the wastewater treatment plant. Conversely, to be able to employ artificial neural systems or the support vector method, one must have specialist computer skills as the models are implemented in the computer software, which could be problematic, especially for small treatment facilities, and also due to additional costs. 


\section{Conclusions}

On the basis of computations, it can be concluded that artificial neural networks, Support Vector Machines and genetic programming can be used to predict activated sludge settleability. The results of analyses indicate that artificial neural networks have the best predictive abilities. That is confirmed by the values of parameters of simulation fit to measurement results for the combinations of data/inputs considered. In the analysed computational variants, slightly worse results, when compared with other methods, were obtained for the Support Vector Machines method. Particular attention should be given to the results obtained with the genetic programming because the model developed using this method is a regression dependence. The latter offers a relatively fast and easy means of finding settleability, without making it necessary to use specialist software. Additionally, the model developed with GP yields practically the same results as the ANN-based model for input data such as wastewater temperature, settleability from the previous measurement and a degree of recirculation.

\section{References}

1. KALINOWSKA E., BONAR G., DUMA J. Principles and practice of wastewater treatment, LEMTECH Konsulting, Kraków 2005 [in Polish]

2. KOCWA-HALUCH R., WOŹNIAKIEWICZ T. Microscopy analysis of activated sludge and its role in the wastewater treatment technological process control. Czasopismo Techniczne Środowisko, 6 (106), 141, 2011 [in Polish].

3. http://www.e-biotechnologia.pl/Artykuly/Wastewatertreatment-activated-sludge-method /2015-07-29 [in Polish]

4. IMHOFF K.K. Urban drainage and wastewater treatment. Oficyna Wydawnicza Projprzem-EKO, Bydgosz 1996 [in Polish].

5. ROMANOWICZ R.J., KICZKO A., NAPIÓRKOWSKI J.J. Stochastic Transfer Function Simulator of a 1-D Flow Routing. Publs. Inst. Geophys. Pol. Acad. Sc., E-10, 406, $151,2008$.

6. BOGER Z. Experience in Developing Models of Industrial Plants by Large Scale Artificial Neural Networks. Intelligent Process Control Systems, 326, 1995.

7. CHUCHRO M. Prediction of biogas production in separate digesters chambers from wastewater treatment plant. Polish Journal of Environmental Studies, 21 (5A), 31, 2012.

8. ZHANG R., HU X. Effluent Quality Prediction of Wastewater Treatment System Based on Small-world Ann. Journal Of Computers, 7 (9), 2136, 2012.

9. ELNEKAVE M., CELIK S.O., TATLIER M., TUFEKCI N. Artificial Neural Network Predictions of Up - Flow Anaerobic Sludge Blanket (UASB) Reactor Performance in the Treatment of Citrus Juice Wastewater. Polish Journal of Environment Study. 21 (1), 49, 2012.
10. HONG Y.S. T., BHAMIDIMARRI R. Evolutionary selforganising modelling of a municipal wastewater treatment plant. Water Research, 37 (6), 1199, 2003.

11. YANG Y.H., GUERGACHI A., KHAN G. Support Vector Machines for Environmental Informatics: Application to Modelling the Nitrogen Removal Processes in Wastewater Treatment Systems, Journal of Environmental Informatics 7 (1), 14, 2012.

12. VERMA A., WEI X., KUSIAK A. Predicting the total suspended solids in wastewater: A data-mining approach. Engineering Applications of Artificial Intelligence, 26 (4), 1366, 2013

13. KUSIAK A., ZENG Y., ZHANG Z. Modeling and analysis of pumps in a wastewater treatment plant: A data-mining approach. Engineering Applications of Artificial Intelligence 26 (4), 1643, 2013.

14. DELLANA S.A., WEST D. Predictive modeling for wastewater applications: Linear and nonlinear approaches. Environmental Modelling \& Software, 24 (1), 2009.

15. KIANMEHR P., MANSOOR W., KFOURY F.A. Prediction of Biogas Generation Profiles in Wastewater Treatment Plants Using Neural Networks. Journal of Clean Energy Technologies, 2 (3), 201, 2014.

16. WEI X., KUSIAK A. Optimization of Biogas Production Process in a Wastewater Treatment Plant. Proceedings of the 2012 Industrial and Systems Engineering Research Conference 2012.

17. GIOKAS D.L., KIM Y., PARASKEVAS P.A., PALEOLOGOS E.K., LEKKAS T.D. A simple empirical model for active sludge thickening clarifiers. Water Research, 36, 3245, 2002.

18. GIOKAS D.L., DAIGGERB G.T., SPERLINGC M. Comparison and evaluation of empirical zone settling velocity parameters based on sludge volume index using a unified settling characteristics database. Water Research, 37, 3821, 2003.

19. STAMOU A.I., GIOKAS D.L., PARASKEVAS P.A. Validation and application of a simple model for circulation secondary settling tanks. Global NEST Journal, 10 (1), 62, 2008.

20. VAPNIK V. Statistical Learning Theory. John Wiley and Sons. New York, 1998.

21. BURGES C. A tutorial on support vector machines for pattern recognition (Knowledge discovery and data mining, Usama Fayyad), Kluwer, 1, 2000.

22. KOZA J.R. Genetic Programming: On the Programming of Computers by Natural Selection, MIT Press, Cambridge, MA. 1992.

23. RUTKOWSKA D., PILIŃSKI M., RUTKOWSKI L. Neural networks, genetic algorithms and fuzzy systems, Wydawnictwo Naukowe PWN, 1997 [in Polish]

24. RAHA D. Exploring Artificial Neural Networks (ANN) Modelling for a Biological Nutrient Removal (BNR) Wastewater Treatment Plant (STP) to Forecast Effluent Suspended Solids, Copyright by Indian Chemical Engineering, 49 (3), 205, 2007.

25. RUTKOWSKI L. Flexible neuro-fuzzy systems: structures, learning and performance evaluation. Springer Science \& Business Media. Kluwer Academic Publisher, 2004. 